\title{
Difficult to Flush
}

National Cancer Institute

\section{Source}

National Cancer Institute. Difficult to Flush. NCI Thesaurus. Code C63317.

The device that is difficult to flush, possibly indicating an obstruction within device. 